\title{
REGIONAL DISTRIBUTION OF FOOD SECURITY AND ITS DETERMINANTS ACROSS REGIONS OF THE PUNJAB, PAKISTAN
}

\author{
Haroon Yousaf ${ }^{1, *}$, Muhammad Usman Zafar ${ }^{2}$, Muhammad Omar Zafar ${ }^{3}$, Shabbir Ahmad ${ }^{1}$ and \\ Qazi Ahmad Raza ${ }^{1}$
}

\author{
${ }^{1}$ Department of Rural Sociology, University of Agriculture, Faisalabad-38040, Pakistan; ${ }^{2}$ Lyallpur Business School, \\ Government College University, Faisalabad-38040, Pakistan; ${ }^{3}$ Department of Sociology Pir Mehr Ali Shah Arid \\ Agriculture University Rawalpindi-46000, Pakistan \\ *Corresponding author's e-mail: h.yousaf89@gmail.com
}

\begin{abstract}
This study was designed to investigate the differences in food security status and its determinants in the regions of the Punjab province (i.e. North, Central and South) of Pakistan. Primary data was collected from 576 rural households situated in six districts (two districts from each region) of the Punjab. Dietary intake assessment (DIA) method was used to examine food security status of the sample households. Results of the study show that food insecurity was highest in South Punjab where $53.6 \%$ of the households were found to be food insecure. While, $43.8 \%$ and $30.2 \%$ of the households were found food insecure in Central and North Punjab respectively. Results of logistic regression model revealed that determinants of food security vary significantly across regions but income of the households was found positively associated with food security status across all the regions while family structure was found negatively associated with food security status. Livestock asset, ownership of agricultural land and family size were found to be significant determinants of food security for Central and South Punjab.
\end{abstract}

Keywords: Food security, spatial distribution, dietary intake assessment, Logit model

\section{INTRODUCTION}

The term food security originated in international development literature in the 1960s and 1970s. Over time, a large number of different definitions of food security have been proposed.

FAO (2015) defined food security as "a situation that exists when all people, at all times, have physical, social and economic access to sufficient, safe and nutritious food that meets their dietary needs and food preferences for an active and healthy life".

According to this definition, food security is comprised of four components i.e. availability, accessibility, utilization and sustainability. Food insecurity or lack of food security situation is due to the nonexistence or inadequacy of any of the above mentioned four conditions at various levels (i.e. household, regional or national). When food intake is consistently inadequate and insufficient to meet the dietary needs of people it is called severe food insecurity or hunger (FAO, 2015). Despite the recent decrease in the number of undernourished people around the world, still, about 795 million people (as shown in figure 1) are food insecure. From these 795 million, 780 million are from developing regions of the world. Situation is even worse in Asia and Africa where 511.7 million and 232.5 million food insecure people live respectively (FAO et al., 2015).

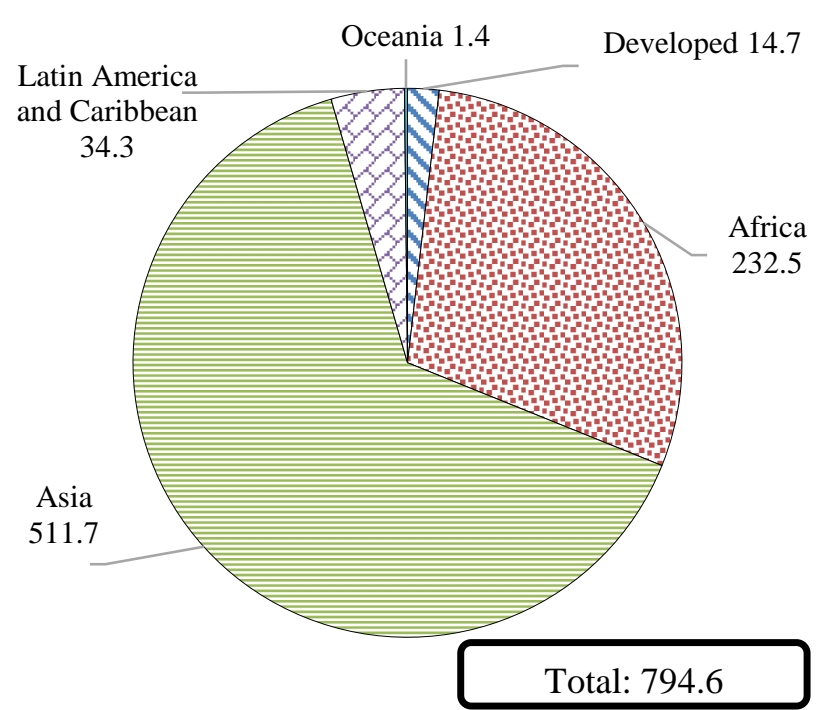

Figure 1. Worldwide distribution of food insecurity. Source: FAO et al. (2015)

The extent of food insecurity varies both spatially and temporally (Iftikhar and Mahmood, 2017). Food security is affected by multiple factors like age and educational status of the household head, family size, farm land size, dependency ratio, livestock asset, income etc. Importance of these factors may vary from society to society and over time. It means one policy to overcome food insecurity is not good enough. We 
need different policies at various levels to tackle food insecurity (Muche et al., 2014).

As noted earlier, having enough food is not sufficient for food security. Countries with sufficient food at national level might also have food insecure people due to unequal distribution of food within country. For example, Pakistan became selfsufficient in food at national level in 1980s and sustains this status (Bashir et al., 2013), yet a considerable proportion population i.e. $22 \%$ is food insecure (FAO et al., 2015). An even greater proportion (58\%) was reported by National Nutrition Survey (NNS, 2011). The Punjab province of Pakistan has major share in country's agricultural production and yet has significant food insecure population i.e. $23 \%$ (Bashir et al., 2013) and 59.5\% (NNS, 2011). The difference between reported food insecure proportions can be explained by sensitivity of food security towards measuring instrument. Bashir et al. (2013) used dietary intake assessment only, while National Nutrition Survey (NNS, 2011) have taken into account caloric intake, anxiety and perceptions of people regarding quality and quantity of food. As noted earlier, food security may vary spatially. This study was designed to check the spatial distribution of food security in rural Punjab. Specifically, it has two objectives i.e., to examine the food security status of the households in different regions of the Punjab and determine the factors affecting household food security status in the areas under study.

\section{MATERIALS AND METHODS}

Province of Punjab has 36 districts which are divided into three regions based on geographical variability. Districts with deserts or mixed typologies of desert and plains formed South Punjab region. Districts with mostly plains situated at less than 350 meters above sea level formed Central Punjab and districts situated between 350 and 900 meters formed North Punjab region. A total of 6 districts ( 2 from each region) were selected randomly. Then from each randomly selected district, 4 villages were selected randomly. On average, every village contains almost 200 households and majority of the households (i.e. $>80 \%$ ) are either small farmer or non-farmer households (GOP, 2010). Data were gathered from 12\% (576) of these households. A structured interview schedule was developed with collaboration of research team that consisted of sociologists and economist to gather information on different facets of food security. Data were gathered in two sections. In first section, demographic and general data of household was gathered; second section was about intake of different food items. All participants provided informed consent (orally) before the survey was started.

Empirical model: Empirical analysis for this study was conducted in two steps. At the first step, households' food security status was measured for each region by calculating per capita calorie intake through Dietary Intake Assessment (DIA) using seven days reference period. Calculated calories were then altered according to age and gender of the household members using caloric adjustment used by National Sample Survey Organization (NSSO, 2007). DIA method was used because it measures actual food consumption and it deals with dietary quality and quantity and can also identify at risk households and individuals. Also, target households in this study are from the less privileged group and they are very vulnerable to being food insecure (Yasin, 2000). For such households, filling their bellies is a bigger concern than eating a tastier food. Different threshold levels of dietary intake were used by different researchers but for this study, threshold level given by Government of Pakistan (2450 Kcal/adult/day) for rural areas (GOP, 2003) was used.

Mathematically, it can be elaborated as

$$
F S_{i j}=\sum_{j=3}^{i=n} F S-T \geq 0
$$

Where, $\mathrm{FS}_{\mathrm{ij}}$ is food security status of $\mathrm{i}^{\text {th }}$ household $(\mathrm{i}=576)$ of $j^{\text {th }}$ category ( $j=$ North, Central and South Punjab) and $T$ is food security threshold for rural areas.

At the second step, to identify food security determinants, binary logistic regression was used because food security (dependent variable) was binary variable. Probability of occurrence of an event can be obtained through logistic regression when a number of independent variables are at work (Hailu and Regassa, 2007).

Suppose food security and socio-economic factors have linear relationship, food security can be elaborated as

$$
F S_{i j}=\sum_{j=2}^{i=n} \beta_{i} S_{i j}+\varepsilon_{i}
$$

Where: $\beta_{\mathrm{i}}$ denotes the coefficients; $S_{\mathrm{i}}$ denotes the vector of socio-economic characteristics; and $\varepsilon_{\mathrm{i}}$ represents error term.

We can rewrite equation 2 as probability of a given household being food secure or insecure using the logistic distribution function narrated by Gujarati (2009) as;

$$
P_{i j}=E\left(F S_{i j}=1 \mid S_{i j}\right)=\beta_{o}+\beta_{i} S_{i j}
$$

Where, $\mathrm{Pij}$ is the probability of ith household of jth category to experience food security and $\mathrm{Sij}$ is the vector of socioeconomic characteristics of ith household of jth category. FSij $=1$ means the household is food secure and now the equation 3 can be rewritten as;

$$
P_{i j}=E\left(F S_{i j}=1 \mid S_{i j}\right)=\frac{1}{1+e^{-\left(\beta_{o}+\beta_{1} S_{i j}\right)}}
$$

For convenience, the equation 4 can as be written as;

Where

$$
\mathrm{P}_{\mathrm{i}}=\frac{1}{1+\mathrm{e}^{-\mathrm{Z}_{\mathrm{i}}}}=\frac{\mathrm{e}^{\mathrm{Z}}}{1+\mathrm{e}^{\mathrm{Z}}}
$$

$$
\begin{aligned}
& Z_{\mathrm{i}}=\beta_{0}+\beta_{1} \mathrm{FSt}+\beta_{2} \mathrm{DRd}+\beta_{3} \mathrm{FmS}+\beta_{4} \mathrm{HHA}+\beta_{5} \mathrm{MI}+ \\
& \beta_{6} \mathrm{LS}+\beta_{7} \mathrm{HHEdu}+\beta_{8} \mathrm{LO}+\beta_{9} \mathrm{DMr}+\beta_{12} \mathrm{EM}+\varepsilon_{\mathrm{I}}
\end{aligned}
$$

Where, $\mathrm{P}(\mathrm{FS} \mathrm{ij})=$ the probability of ith household from $\mathrm{jth}$ category to become food secure ( 1 for food secure, 0 otherwise), $B 0=$ constant term, $B 1-12=$ coefficients of socioeconomic variables, 
$\beta 0=$ constant term

B1-12 = coefficients of socio-economic variables

FSt $=$ family structure of the household (Nuclear or Joint)

$\mathrm{DRd}=$ distance between household and road

$\mathrm{DMr}=$ distance between household and market

$\mathrm{FmS}=$ family size

HHA = household head's age

MI = monthly income (Pakistani Rupees) from all sources

LS = livestock asset

HHEdu = household head's education level (years of schooling)

LO = land owned (acres)

$\mathrm{EM}=$ total earning members in the household

Demographics of study participants: Table 1 shows that about $20 \%$ households from North Punjab, about 14\% from Central and about $22 \%$ from South Punjab region had household heads with age up to 35 years. A little less than half, about $48 \%$ of the sample households from North Punjab, about $60 \%$ from Central Punjab and about 55\% from South Punjab had household heads with age between 36 to 55 years representing active age group. About 19\% households from North Punjab, about $15 \%$ from Central Punjab and $20 \%$ from South Punjab had up to 4 members. While, more than half, about 53\% households from North Punjab, about 53\% from Central and about $56 \%$ from South Punjab had 5 to 8 household members. About $27 \%$ households from North Punjab, about 32\% from Central and about 33\% households from South Punjab had more than 8 household members.
About $43 \%, 53.1 \%$ and about $41 \%$ households from North, Central and South Punjab respectively had only one earning member in the household. About 47\%, 36\% and 47\% households from North, Central and South Punjab respectively had 2-3 earning member in the household. Half of the households from North Punjab, about $48 \%$ from Central and about 38\% households from South Punjab had nuclear family system. Another half of the households from north Punjab, more than half from central $(52 \%)$ and south (61.5\%) Punjab had joint family system. About $39 \%$ of the household heads from north Punjab, about $40 \%$ from central and about $46 \%$ from south Punjab were illiterate. About $22 \%$ of the household heads from north Punjab, about $16 \%$ from central and about $18 \%$ from south Punjab had 10 years of schooling.

\section{RESULTS}

The results of Dietary Intake Assessment (DIA) in three regions of the Punjab are presented in Table 2. Overall, food security situation in Punjab was not satisfactory (i.e. a sizable portion of population was food insecure) but households from South Punjab were found to be the most food insecure with almost (54\% food insecure households). Situation was better in Central Punjab with about $44 \%$ food insecure households. While, North Punjab was found most food secure region with $30 \%$ food insecure households. The average calorie intake of

Table 1. Demographic characteristics of the respondents.

\begin{tabular}{lcccc}
\hline Variables & North & Central & South & Total \\
\cline { 2 - 4 } & $\mathbf{f ( \% )}$ & $\mathbf{f ( \% )}$ & $\mathbf{f ( \% )}$ & $\mathbf{f}(\boldsymbol{\%})$ \\
\hline Age & & & & \\
Up to 35 & $38(19.8)$ & $26(13.5)$ & $42(21.9)$ & $106(18.4)$ \\
$36-55$ & $93(48.4)$ & $111(57.8)$ & $106(55.2)$ & $310(53.8)$ \\
$>55$ & $61(31.8)$ & $55(28.6)$ & $44(22.9)$ & $160(27.8)$ \\
Family size & & & \\
Up to & $37(19.3)$ & $28(14.6)$ & $21(10.9)$ & $86(14.9)$ \\
5-8 & $103(53.6)$ & $102(53.1)$ & $107(55.7)$ & $312(54.2)$ \\
$>8$ & $52(27.1)$ & $62(32.3)$ & $64(33.4)$ & $178(30.9)$ \\
Earning members & & & & \\
1 & $83(43.2)$ & $102(53.1)$ & $78(40.6)$ & $263(45.7)$ \\
2-3 & $91(47.4)$ & $69(36.0)$ & $90(46.9)$ & $250(43.4)$ \\
$>3$ & $18(9.4)$ & $21(10.9)$ & $24(12.5)$ & $63(10.9)$ \\
Family structure & & & & \\
Nuclear & $97(50.5)$ & $92(47.9)$ & $74(38.5)$ & $263(45.7)$ \\
Joint & $95(49.5)$ & $100(52.1)$ & $118(61.5)$ & $313(54.3)$ \\
Education of HH & & & & \\
Illiterate & $75(39.1)$ & $76(39.6)$ & $88(45.8)$ & $239(41.5)$ \\
Primary (5 years) & $29(15.1)$ & $37(19.3)$ & $33(17.2)$ & $99(17.2)$ \\
Middle (8 years) & $30(15.6)$ & $37(19.3)$ & $28(14.6)$ & $95(16.5)$ \\
Matric (10 years) & $43(22.4)$ & $30(15.6)$ & $34(17.7)$ & $107(18.6)$ \\
$>$ 10 & $15(7.8)$ & $12(6.3)$ & $9(4.7)$ & $36(6.3)$ \\
\hline
\end{tabular}


Yousaf, Zafar, Zafar, Ahmad \& Raza

Table 2. Regional distribution of food security/insecurity in Punjab Province.

\begin{tabular}{lcccc}
\hline Food security status (DIA) & North & Central & South & Total \\
\cline { 2 - 5 } & $\mathbf{f}(\boldsymbol{\%})$ & $\mathbf{f}(\boldsymbol{\%})$ & $\mathbf{f}(\boldsymbol{\%})$ & $\mathbf{f}(\boldsymbol{\%})$ \\
\hline Secure & $134(69.8)$ & $108(56.3)$ & $89(46.4)$ & $331(57.5)$ \\
Insecure & $58(30.2)$ & $84(43.8)$ & $103(53.6)$ & $245(42.5)$ \\
Minimum* & 817.0 & 832.4 & 563.0 & 563.0 \\
Maximum* & 5038.3 & 5161.4 & 4768.5 & 5161.4 \\
Mean \pm SD* & $2372.3 \pm 761.5$ & $2436.1 \pm 794.4$ & $2262.3 \pm 726.7$ & $2356.9 \pm 763.4$ \\
\hline
\end{tabular}

*Calorie intake

Table 3. Determinants of food security by regions.

\begin{tabular}{|c|c|c|c|c|c|c|}
\hline \multirow[t]{2}{*}{ Variables } & \multicolumn{2}{|l|}{ North } & \multicolumn{2}{|c|}{ Central } & \multicolumn{2}{|c|}{ South } \\
\hline & $\mathbf{B}$ & OR & $\mathbf{B}$ & OR & $\mathbf{B}$ & OR \\
\hline FSt & $-3.07(0.52) * *$ & 0.08 & $-5.35(0.85)^{* *}$ & 0.06 & $-2.00(0.44)^{* *}$ & 0.135 \\
\hline MI & $0.0001(0.00)^{* *}$ & 1.0001 & $0.0001(0.00) *$ & 1.0001 & $0.0001(0.00)^{* *}$ & 1.0001 \\
\hline FmS & $-0.04(0.07)$ & 0.97 & $-0.46(0.13)^{* *}$ & 0.631 & $-0.33(0.08)^{* *}$ & 0.720 \\
\hline LS & $1.08(0.46)^{*}$ & 0.34 & $1.17(0.72)$ & 1.621 & $0.90(0.44)^{*}$ & 0.406 \\
\hline LO & $0.11(0.06)$ & 1.11 & $0.16(0.05)^{* *}$ & 1.173 & $0.11(0.03)^{* *}$ & 1.111 \\
\hline HHEdu & $0.41(0.16)^{*}$ & 0.66 & $0.31(0.22)$ & 0.735 & $0.24(0.11)^{*}$ & 1.271 \\
\hline HHA & $0.03(0.02)$ & 1.03 & $0.02(0.02)$ & 0.976 & $0.03(0.02)^{*}$ & 1.034 \\
\hline EM & $0.09(0.19)$ & 1.09 & $0.81(0.31)^{* *}$ & 1.31 & $0.16(0.16)$ & 1.172 \\
\hline DRd & $-0.07(0.07)$ & 0.94 & $-0.18(0.07)$ & 1.196 & $-0.22(0.12)$ & 0.801 \\
\hline $\mathrm{DMr}$ & $-0.03(0.03)$ & 1.03 & $-0.01(0.04)$ & 1.008 & $-0.07(0.04)$ & 1.069 \\
\hline Constant & $3.67(1.45)^{*}$ & & $7.49(1.92)^{* *}$ & & $2.56(1.29)^{*}$ & \\
\hline Log likelihood & 162.00 & & 100.2 & & 168.33 & \\
\hline $\begin{array}{l}\mathrm{H}-\mathrm{L} \text { model }(\mathrm{df}=8) \\
\text { significance test results }\end{array}$ & 18.741 (p value & $.016)$ & 8.865 (p valu & $0.354)$ & 13.092 (p valu & $0.109)$ \\
\hline Cox \& Snell R ${ }^{2}$ & 0.418 & & 0.57 & & 0.353 & \\
\hline Nagelkerke $\mathrm{R}^{2}$ & 0.558 & & 0.76 & & 0.483 & \\
\hline
\end{tabular}

North, Central and South Punjab was 2372.3 $\pm 761.5,2436.1$ \pm 794.4 and $2262.3 \pm 726.7$, respectively.

Determinants of food security: Binary logistic regression was used to check the effect of socio-economic variables on household food security in three regions of the Punjab province. The estimations of relative risk in binary logit models were calculated by odds-ratios (OR). The findings of logistic regression model (Table 3) indicate that out of ten variables in all three models, four (household head's education, family structure, monthly income, livestock asset), six (land ownership, family structure, earning members, family size, monthly income and distance from road) and seven (household head's education, land ownership, family structure, household head's age, family size, monthly income and livestock asset) variables were found important determinants for North, Central and South Punjab respectively. Significant results are explained below.

Family structure (FSt): Family structure refers to the combination of relatives that comprise a family. In Pakistan two family structures are common i.e. joint and nuclear family. It was found that households with nuclear families were $92 \%, 94 \%$ and $86.5 \%$ more food secure than households with joint families in North, Central and South Punjab, respectively.

Monthly income (MI): This had positive effect on food security for all the regions. Results show that if income increased by one Pakistani Rupee (Rs), the probability of food security for a household also increase by the factor associated with odds ratio. Odds-ratio based on Rs. 1000 increase $\left(\exp ^{0.00007 * 1000} \exp ^{0.00006 * 1000}\right.$ and $\left.\exp ^{.00009 * 1000}\right)$ were 1.072, 1.061 and 1.094 for North, Central and South Punjab respectively that were then transformed into percentages. An increase in monthly income by of Rs. 1000 contributed to increasing the probability of a household to experience food security by $7.2 \%, 6.1 \%$ and $9.4 \%$ in North, Central and South Punjab, respectively.

Family size (FmS): Family size was found as an important determinant for Central and South Punjab. The negative sign indicates that family size and food security are inversely related. An increase of one family member decreases household food security by $37 \%$ and $28 \%$ in Central and South Punjab, respectively.

Livestock $(\boldsymbol{L S})$ : Livestock was found to affect household's food security status positively in North and South Punjab. 
This impact was relatively smaller in Central Punjab. Addition of one livestock animal increased the probability of food security by $66 \%$ and $59 \%$ in North and South Punjab, respectively.

Land ownership (LO): The ownership of agricultural land was found significant determinant of food security in Central and South Punjab. Addition of one acre of agricultural land increased the probability of a household to become food secure by $17 \%$ in Central and by $11 \%$ in South Punjab.

Household heads' education (HHEdu): This was positively and significantly associated with food security status of North and South Punjab. An extra year of schooling of a household head in North and South Punjab was responsible for $34 \%$ and $27 \%$ increase in the chances of household's food security, respectively.

Household head's Age (HHA): was statistically significant with a positive sign for South Punjab which implies that as household head's age increases, the probability of the household being food secure also increases. Results revealed that an extra year of household head's age increases the probability of food security by $3.4 \%$ in South Punjab.

Earning members (EM): Number of earning members was found significant determinant of food security in Central Punjab. More earning members mean higher income and higher household income ensures food security. In Central Punjab, an addition of one earning member in the household increases the probability of being food secure by $31 \%$.

Table 4 presents the relative importance of determinants according to their impact on food security for households from each region. For households from North Punjab, livestock asset had the most significant positive impact followed by education and then income. For Central Punjab, earning members had the most significant impact on food security followed by land ownership and then income. For South Punjab, livestock had the most significant effect on food security followed by education, land ownership, income and then age. Family structure (dummy variable) showed the most significant negative effect on food security for every region followed by family size in Central and South Punjab. This ranking of determinants of food security can be used to inform policy development around overcoming food insecurity.

\section{DISCUSSION}

The results of this study show that the overall condition of food security in Punjab is not satisfactory. Sampled households from South Punjab are found the most food insecure followed by Central Punjab and North Punjab was found least food insecure. This variability in food security status can be explained by the fact that South Punjab is least developed region of the Punjab and in this survey, it was found that South Punjab has on average bigger family size, less educated household heads and greater number of joint families as compared to other regions. All these factors contribute to South Punjab's food insecurity status. Sampled households from North Punjab on average performed better on these variables and made North Punjab most food secure region compared to Central and South.

Results of logistic regression model show that determinants of food security also vary by regions.

Family structure has significant impact on food security status of the households from every region. It is normally perceived that joint families are more food secure than nuclear ones because they can bring their resources together under a common household head. Contrary to this perception, in this study nuclear families were found more food secure than joint ones. This finding can be explained by the fact that joint families in Pakistan have a higher rate of dependency ratios which makes a household vulnerable to food insecurity. Bashir et al. (2013) also found that in Punjab, Pakistan households with nuclear family structure were more food secure than joint ones and this relationship was found to be significant at $\mathrm{p}<0.01$.

Income is also an important indicator of food security. Having enough food in town does not mean anything unless people have enough money to buy it. Households with higher income were found to be more food secure in every region. Shahid et al. (2014) also found that higher income of a household is positively associated with its food security status at $\mathrm{p}<0.05$.

Table 4. Comparison of the ranks of significant factors.

\begin{tabular}{|c|c|c|c|c|c|c|}
\hline \multirow{2}{*}{ Ranks } & \multicolumn{2}{|c|}{ North Punjab } & \multicolumn{2}{|c|}{ Central Punjab } & \multicolumn{2}{|c|}{ South Punjab } \\
\hline & Factors & Impact & Factors & Impact & Factors & Impact \\
\hline \multicolumn{7}{|c|}{ Positive impacts } \\
\hline 1 & Livestock & $66 \%$ & Earning members & $31 \%$ & Livestock & $59.4 \%$ \\
\hline 2 & Education & $34 \%$ & Land ownership & $17.3 \%$ & Education & $27 \%$ \\
\hline 3 & Monthly income & $7.2 \%$ & Monthly income & $6.1 \%$ & Land ownership & $11 \%$ \\
\hline 4 & & & & & Monthly income & $9.4 \%$ \\
\hline 5 & & & & & Age & $3.4 \%$ \\
\hline \multicolumn{7}{|c|}{ Negative impacts } \\
\hline 1 & Family structure & $92 \%$ & Family structure & $94 \%$ & Family structure & $86.5 \%$ \\
\hline 2 & & & Family size & $37 \%$ & Family size & $28 \%$ \\
\hline
\end{tabular}


Family size is another important indicator of food security as reported by previous researches. It would take more resources to feed a larger family which is difficult especially when dependency ratio within a family is high. Family size was found negatively and significantly associated with food security status of sampled households from Central and South Punjab. Bashir et al. (2013b), also reported negative relationship between family size and food security status. They stated that addition of one family member decreases the probability of the household of being food secure by $31 \%$. Muhoyi et al. (2014) also reported that, in Zimbabwe, food security is negatively associated with family size and each additional member in household reduces the probability of being food secure by $7 \%$.

Ownership of livestock asset was also found significant determinant of food security for households from North and South Punjab. Livestock in rural areas is raised by almost every household. It does not only serve the household's need of milk but surplus milk is sold for cash income. Livestock is also used for meat and sold when a household is in need of money. So, the importance of livestock in the context of food security is manifold. In Ethiopia, Muche et al. (2014) also found that addition of one livestock animal improves the odds of food security by $43.1 \%$. Muhoyi et al. (2014) also found similar relationship between food security and livestock asset. They reported that livestock variable was positive and significant at the 5\% level. Ownership of an additional animal increases the likelihood of household to experience food secure by $3 \%$.

In this study education of household head was found positively significant for food security status of the households from South Punjab. With better education, household heads can claim better jobs and can also adopt new agricultural techniques (in case of farmer household) to increase productivity which will ultimately result in improved food security status. Similarly, Otunaiya and Ibidunni (2014) also found that, in Nigeria, educational status of household head was significant at $\mathrm{p}<0.01$, implying that increase in education of household head would result in improved food security status of the household.

Age of the household head was also positively significant for food security status of households from Central Punjab. Older household heads have more experience that can be used for both increase in income and efficient spending of income and both can lead to food security. Dzanja et al. (2015) also reported that, in Malawi, household head's age and food security status of household were significantly associated with each other at $\mathrm{p}<0.05$.

Number of earning members in a household was found positively significant for food security of households from Central Punjab. More number of earning members means more income which ultimately results in improved food security status. Bashir et al. (2013b) also found significant relationship between number of earning members and food security at $p<0.05$. Similarly, in Nigeria, Otunaiya and Ibidunni (2014) found that dependency ratio is negatively and significantly $(-0.256)$ associated with food security at $\mathrm{p}<0.01$.

Conclusion: It is statistically proven that households from each region of Punjab experience various levels of food security. According to the findings of this study as we go from North to South, level of food insecurity increases. Determinants of food security also vary by each region when ranked according to their importance to food security. Family structure and monthly income were significant determinants for all the regions. Results suggest that a single policy cannot be used to overcome the food insecurity issue in the different regions of Punjab. Different kind of policy focus, based on the determinants, is required to tackle food insecurity in each region of Punjab. Further research is needed to examine whether food security status and its determinants vary for rural and urban households.

\section{REFERENCES}

Bashir, M.K., S. Schilizzi and R. Pandit. 2013. Impact of socio-economic characteristics of rural households on food security: the case of the Punjab, Pakistan. J. Anim. Plant Sci. 23:611-618.

Bashir, M.K., S. Schilizzi and R. Pandit. 2013b. Regional sensitivity of rural household food security: The case of Punjab, Pakistan. J. Anim. Plant Sci. 23:1200-1206.

Dzanja, J.L., M. Christie, I. Fazey and T. Hyde. 2015. The role of social capital on rural food security: the case study of Dowa and Lilongwe Districts in Central Malawi. Int. J. Agric. Sci.1:46-56.

FAO, IFAD and WFP. 2015. The state of food insecurity in the world 2015. Meeting the 2015 International Hunger Targets: Taking Stock of Uneven Progress, Rome, Italy.

FAO. 2015. The state of food insecurity in the world. Meeting the 2015 international hunger targets: Taking stock of uneven progress, FAO Rome. Available online at http://www.fao.org/3/a-i6030e.pdf

GOP. 2003. Economic Survey of Pakistan, 2002-03. Ministry of food and agriculture. Finance Division, Economic Advisor's Wing, Islamabad, Pakistan.

GOP. 2010. Economic Survey of Pakistan, 2009-10. Ministry of Food and Agriculture. Finance Division, Economic Advisor's Wing, Islamabad, Pakistan.

Hailu, A. and N. Regassa. 2007. Correlates of household food security in densely populated areas of Southern Ethiopia: does the household structure matter. Stud. Home Com. Sci. 1:85-91.

Iftikhar, S. and H.Z. Mahmood. 2017. Spatial distribution of agricultural resources and food security: A case of Punjab Pakistan. Cogent Food Agric. 3:35-45. 
Muche, M., B. Endalew and T. Koricho. 2014. Determinants of household food security among Southwest Ethiopia rural households. Food Sci. Technol. 2:93-100.

Muhoyi, E., T.J. Mukura, D. Ndedzu, T. Makova and O. Munamati. 2014. Determinants of household food security in Murehwa district, Zimbabwe. J. Econ. Sust. Dev. 5:84-92.

NNS. 2011. National Nutrition Survey of Pakistan. Nutrition Wing, Cabinet Division, Government of Pakistan.

NSSO. 2007. Nutritional Intake in India 2004-2005. National Sample Survey Organization (Report No. 513). Ministry of Statistics and Program Implementation. Available online at http://mospi.nic.in/rept\%20_\%20 pubn/513_final.pdf
Otunaiya, A.O. and O.S. Ibidunni. 2014. Determinants of food security among rural farming households in Ogun State, Nigeria. J. Sust. Dev. Afr. 16:33-44.

Shahid, M., T. Aqeela, A.K. Shahbaz and J. Norina. 2014. An investigation of determinants of food security in rural areas of Faisalabad, Pakistan. Mediterr. J. Soc. Sci. 5:676-680.

Yasin, M.A. 2000. An investigation into food security situation in rain-fed areas of district Rawalpindi. M.Sc. (Hons.) Diss., Inst. Agric. and Resour. Econ., Univ. Agric. Faisalabad, Pakistan. 